Responding to Diversity: Differentiating in the Language Arts Classroom

\title{
Ruthanne Tobin
}

University of Windsor 
Allie is a very bright, talkative sixth-grader who reads voraciously. She finds some of her class work interesting but often sits idly waiting for others to catch on to concepts she already knows. She belongs to an after-school drama club, where she is known not so much for her acting but for her leadership and her tendency to direct and rewrite the play. Her teacher has done some curriculum compacting with Allie and she has also facilitated a mentorship with the school librarian.

Steven is a gifted eleven year-old who has a learning disability. While he receives three hours of pull-out support each week with his learning support teacher, his school has no program for gifted learners. His written work is rather weak, with written responses to his in-class readings totalling two to three sentences, at best. He loves to read comic books, brings his own supply to class, and reads up on his heroes at www.marvel.com. His teacher has reported that he is most engaged when he creates elaborate drawings of mythical heroes in his notebooks.

Kelly loves to learn but finds it very difficult to stay organized. She frequently loses her school belongings and often arrives at school a half-hour late for her Grade 6 language arts class. She is a reluctant reader and writer and her reading has been assessed at about a Grade 3 level. When she goes to the school library, she likes to read magazines about outdoor adventures and after school can be found at the Climbing Wall. She comes from a single parent home where her mother works at two jobs and often does not have the time to take her to the public library. There are few reading opportunities for her in her home community.

Sindu joined her Grade 6 class shortly after arriving from India three months ago. She is participating in the school's English as a Second Language support program three afternoons a week, but the rest of the time she sits quietly and prefers to work alone. Her English language 
assessment results placed her at a beginner level in English, and her bilingual assessment of academic skills placed her at the Grade 6 level. Her parents have always supported Sindu's school efforts in India and they continue to send her to Punjabi school on Saturday morning. Sindu's school district does not have English reception classes, so she spends all but three afternoons in the regular classroom.

These students are typical of the academic, linguistic, and cultural diversity that many Canadian teachers see in regular classrooms on a daily basis. For these students, and others like them, differentiation in the regular classroom could make a critical difference in their lives. Probably more than any other area of the curriculum, language arts requires differentiation on behalf of students as diverse in needs as Allie, Steven, Kelly, and Sindu. In fact, Singer \& Donlan (1989) estimate that a reading-ability span in a typical classroom would be two-thirds of the average chronological age of the students. In a typical class of eleven-year-olds, a teacher could expect a seven year range of reading levels. Additionally, if the regular classroom teacher doesn't know how to deal with Steven's learning disability and his advanced ability, his gifts may never be developed properly, and he is likely to focus more on what he can't do than what he can do (Baum, Cooper \& New, 2001). Sindu, despite her ESL support time, still spends most of her day in the regular classroom and requires materials and instruction that take into account her high conceptual knowledge and her low English language ability. Kelly's fluency in reading is unlikely to improve without getting the right level of books in her hands, particularly books that would appeal to her interest in outdoor life. As a voracious reader, Allie also needs her classroom teacher to understand that she requires a robust curriculum that includes challenging reading materials and advanced curriculum. Allie, Kelly, Steven, and Sindu all need a classroom in which the language arts curriculum and instruction are differentiated. 
In preparing this article, I reviewed the literature for answers to two questions: What is differentiated instruction? In what ways do teachers differentiate for the wide range and diversity of learners in the context of language arts during the middle years (grades 5-8). I examined journals in these areas: language arts, special education, gifted education and English as a second language mostly between the years 1998-2004. Based on this analysis, I identified five approaches: (a) choices in reading materials and creative work products; (b) a discussionbased framework focused on big ideas; (c) dynamic grouping (d) universal design in whole class literacy instruction; and (e) access to multimedia. Meeting the needs of students who are different (students with learning disabilities, ESL students, struggling readers and writers, students who are gifted) through the use of such approaches requires a responsive and respectful teaching disposition and a willingness to share teacher power. At the heart of differentiation is a desire for improvements in how we meet the needs of an increasingly diverse Canadian school population.

\section{Differentiation: responding to readiness, interest or need.}

Differentiation was originally associated with gifted learners (e.g. Renzulli, 1978; 1997 Tannenbaum \& Baldwin, 1983; VanTassel-Baska, 1992). In the last several years, it has become more of a mainstream interest, partly because of the inclusion movement (Hutchinson, 2002) and also because of the tendency to enroll speakers of languages other than English directly into regular classes (Cummins, 2000). Differentiation was popularized by Tomlinson's (1995) extensive and well-articulated work on whole-class differentiation. Three broad conceptions of differentiation have emerged from the research: (1) eliciting learner responses commensurate with student abilities and talents (Tieso, 2003); (2) facilitating the use of instructional materials that are most appropriate for the reading ability of the student (Ivey, 2000); and (3) ensuring that 
what a student learns, how he/she learns, and how the student demonstrates what he/she has learned is a match for that student's readiness level, interests, and preferred mode of learning (Tomlinson, 2004).

The key elements of differentiating classroom activity are modifying the content, modifying the process (sometimes called the sense-making activities [Pettig, 2000]), and modifying products of student learning in accordance with the three key student characteristicsreadiness, interests, and learning profile (Tomlinson, 1995). Readiness is a student's entry point in relation to a particular understanding or skill. On one hand, students with less-developed readiness may need explicit help in closing the gaps in their learning, more opportunities for direct instruction, activities or products that are more structured or more concrete, or learning activities that require greater dependence or more scaffolding by the teacher. Advanced students, on the other hand, may need to skip steps or activities and products that are quite complex, or work that is multi-faceted (Tomlinson, 1999). For example, Sindu's readiness to participate in an upcoming class discussion on drug addiction through the introduction of the book The House that Crack Built (Taylor, 1992) will be limited because of her inchoate command of the English language. She would benefit from direct instruction that would allow her to preview the vocabulary supported by pictures, and from participation in small group discussion of the main theme. There is also a cultural gap because Sindu is unlikely to be aware of the nursery rhyme on which this book for middle-grade students is structured (This Is The House That Jack Built, Adams, 1978). If Sindu were given some one-on-one time to become familiar with these two components of the story, she could follow the gist of the discussion and profit from the differentiated literacy response activities planned by the teacher. 
The second key characteristic is the student's interests (Renzulli, 1997; Tomlinson, 1995), which refers to a child's affinity for a topic or skill. In Kelly's case, a couple of key components in supporting her reading improvement would be to draw on her interest in outdoor adventures, and to consider her reading level, when selecting her reading materials (Worthy, Patterson, Salas, Prater, \& Turner, 2002). Selection of materials that are interesting and relevant to students positively affects learning, motivation, effort, and attitudes (Fink, 1995/6; Hidi, 1991; Schiefele, 1991). One of the most common challenges among students with learning disabilities (LD) is an ability to focus and sustain attention, yet when engaged in areas of strength and interest, and engaged in positive social interaction around literacy, students like Kelly who struggle with reading and writing show high levels of motivation to read (Worthy et al., 2002). Students like Steven, who require dual differentiation, also exhibit high levels of task commitment in overcoming problems and are able to create high-quality products when personal interests are factored into curriculum and instruction decisions (Baum, Renzulli, \& Hebert, 1995; Tannenbaum, 1983). Using interest-based curriculum provides a context in which students are most likely to sustain attention (Renzuilli, 1997).

The third key characteristic is a student's learning profile (Tomlinson, 1999) which has to do with how a student learns, and encompasses intelligences, learning preferences, and learning needs. Early in the school year, much of the information about a student's learning profile may be obtained from school records or from professionals who have worked with the student in previous years. In Steven's case, it would embrace what we know about his needs as a learner with LD - that he often needs explicit scaffolds and dialogue in order to bridge the gap between oral and written language (MacArthur, Schwartz, Graham, Molloy \& Harris, 1996), and what we know about his divergent thinking - that he has many creative ideas and likes to express these 
through his pencil drawings, followed up by the teacher scribing of his imaginative ideas for the captions.

Differentiating does not mean that a teacher is taking into account the individual interests, profiles, and readiness of the thirty students five hours per day, in every curricular and instructional decision, simultaneously. To suggest that would be ludicrous. Rather, differentiating means that a teacher is approaching the curriculum with a responsive disposition - an orientation to planning, decision-making, curriculum selection, and instructional flow that is flexible and opportunistic. Teachers share some of their power with their students about what is to be learned and how to learn it. In the following section, I highlight five approaches that teachers use as starting places to address the range of diversity and ability within their classes.

\section{Differentiation in the Language Arts Classroom: Five Starting Places}

\section{Choices in Reading Materials and Creative Work Products}

At the heart of a differentiated curriculum in language arts is the need to provide learners with choices about what they read and about the design of their work products. This seems so basic, yet many classrooms are still stocked with class sets of perhaps six to eight (albeit awardwinning) novels and all students are "involved" in doing the same two or three types of novelstudy assignments. This limited selection of readings and common work menu has little to offer students like Allie, Steven, Kelly, or Sindu. Winebrenner (2001), in reference to the most frequent complaint she hears about underachievers - "They won't do their work". - suggests that the reality may be closer to" They won't do the teacher's work, but would be more than willing to work on what is meaningful for them." One solution is the implementation of learning contracts, which offer a means of orchestrating child-centeredness and increased independence 
(Greenwood, 2002). The teacher serves as facilitator and enabler, negotiating with and advising the student in setting up the learning contract, yet gives the student some say in what and how he/she will learn. The student in turn, agrees to complete tasks in a set amount of time on his or her own initiative.

A better-known approach in which the child is assumed to be different, to have special interests and abilities, and to have differences that are normal is the reading workshop, which provides a venue for focusing on the strengths and needs of each student (Atwell, 1998; Roller, 1996). The reading workshop consists of five components: teacher sharing time, focus lessons, conference, self-selected reading, responding time, and student sharing time. To determine that a book is at an appropriate level for a student, Towle (2000) advocates that teachers use a combination of a running record and retelling, whereby a student reads a short passage aloud, to provide the teacher with information about a student's fluency and miscues. Then the student retells, verbally or in writing, the main idea and supporting details of the passage, providing the teacher with the necessary information to determine if the book is at an appropriate level. During responding time-which usually lasts 40 to 60 minutes at the grade 6 level - students are involved in literature circles, writing in a journal, special projects, and individual reading conferences with the teacher. Student work is individually differentiated the moment the student chooses a reading selection (guided by the teacher) through to the student response. In order for reading workshop to work effectively, classroom libraries need to be well stocked and the books categorized according to reading level and genre, so that the student can easily determine whether a book is appropriate for her/him.

Another way of differentiating specific literacy products is through tiered activities (Tomlinson, 1999), which allow learners to respond on one of three levels of complexity, 
according to their readiness. Tiered activities take into account the degree of structure and complexity required by the learner. For example, in response to a reading of The House that Crack Built (Taylor, 1992) some grade 6 students, including Sindu, may respond to one of the two evocative pictures and to note, in their own words or through drawings, some of the feelings that the pictures evoke. They then discuss the reading in cooperative groups, using guiding questions that unveil some of the essential themes of the story such as interdependence, choice, and drug addiction. Other students, like Steven, who simultaneously need more explicitness and divergence may be supplied with the repetitive verse from the story to aid in retelling the first five events, and then be invited to change any one event to affect the story's outcome. More advanced students, like Allie, could be asked to write a persuasive book-jacket review and to stage a tableau of one of the provocative scenes from the text. Providing a menu of work products along a continuum of complexity focused on a key piece of literature increases the likelihood that learners will become engaged in more challenging work. Students who are new to a differentiated classroom setting would need guidance in selecting work products that are appropriate for their needs, interests and readiness.

The reading workshop and learning contract approaches also address the criticism that adolescents do not so much lose interest in reading per se, as lose interest in the kinds of reading they are typically required to do in school, for example reading textbooks and certain teacherselected texts (Worthy, 1996). For older readers who struggle, like Kelly, or for English language learners like Sindu, Fielding and Roller's (1992) principle of making difficult books accessible and easy books acceptable is just as important for them as it is for younger readers. For students like Kelly who rarely get to the library outside of school, the classroom library can level the playing field (Hunter, 1999) and facilitate differentiated instruction. 
Facilitating creative work products is also an important aspect of differentiation. Students discover meaningful dimensions of literacy when they can explore them through creative arts (Wilson, 1997). Paradoxically, such creative expressions in the language arts often decrease in focus as learners move up into the middle school grades yet it is exactly at this age that learners can be more independent in accessing creative and interesting resources for their learning.

Aesthetic and creative responses to text in the form of dance, drawing and interactions with popular culture (Dyson, 2003; Morrell, 2002; Newkirk, 2002) open up myriad avenues of expression and differentiated opportunities for learners. One such trend capitalizes on the current popularity of comic books, largely due to the surging popularity of Japanese animation (better known as anime) (Toku, 2001; Mann, 2004). Bitz's (2004) research on using comic book writing and design with inner-city students showed that students (rather than focusing on superheroes, science fiction or fantasized stories) focused instead on the themes of their own individual lives. There was noticeable improvement in their writing especially for students with limited English proficiency partly because of their ability to rely on the pictorial components as they were involved in creating their own comic books (Blitz, 2004).

It is also important not to overlook more traditional, low-tech, and easy-to-access resources such as taped interviews, and books on tape which can provide rich sources of information relevant to the students' interests or chosen topics of inquiry which can be pursued individually or in small groups. Encouraging the use of expository magazines, which often includes many labelled pictures and diagrams, also supports learners who struggle with traditional books as does inviting artists/mentors to the classroom to demonstrate a technique that students first observe and then apply. When gifted students with learning disabilities like Steven are given opportunities to use a variety of presentation methods other than traditional written 
products to represent what they know like acting out an interpretation of a story, presenting a slide-tape show, drawing a series of cartoons- they can produce advanced products (Baum et al., 1995).

\section{Discussion-Based Approach Focused On Big Ideas}

In recent years, schools across Canada and the U.S. have undergone curriculum reform, which has resulted in the proliferation of learning expectations (sometimes called outcomes) set by most provinces and states. Long lists of such expectations have come under criticism because of their tendency to influence teachers to focus on exposure as opposed to understanding (Kameenui \& Carnine, 1998). Only the highest performing students are likely to learn, understand, and subsequently apply knowledge when they are simply exposed to concepts. The theory of social constructivism suggests that individuals make meaning from text (or speech, or viewing) and that the social and cultural context heavily influences the interpretations. Vygotsky (1962) maintained that the nature of language learning shifts in early adolescence to encompass more of a social context; that is, language proficiency parallels the growth in the overall psychological and social development of students aged 10-14. Young adolescents actually strive to make sense of their learning by relating it to their new social interests and psychological awareness. All students need opportunities to interact with big ideas and to deepen their understanding through meaningful conversations and collaborative groupings. High-quality discussion and exploration of ideas - not just the presentation of high-quality content by the teacher or text - are critical experiences for readers \& writers (Eeds \& Wells, 1989, Gambrell \& Almasi, 1996; Guthrie, Schafer, Wang, \& Afflerbach, 1995). High-quality discussions are influenced by (a) the use of authentic questions, which are used to explore differing understandings of a text; (b) "uptake", in which the teacher's questions "take up" and build on a 
student's previous comment and/or on the intended message of the student, not just the words (both of which create continuity in the discourse); and (c) substantial time for whole-class discourse devoted to a free exchange of ideas among students (Nystrand, 1997; Wells, 2001). Students need time and support for their ever-growing and changing "envisionment" of a text-a term Langer (1995) uses to describe a mixture of understandings, questions, hypotheses, and connections to previous knowledge and experiences.

Different interpretations of text instead of consensus interpretation is a key way in which learners can be encouraged in differentiated classrooms to bring their own understandings and life experiences to the readings. In particular, struggling readers like Kelly, and second-language learners like Sindu, typically do much better when instruction builds on previous knowledge and permits them to voice their understandings and to refine those understandings through substantive discussions with others (Langer, Bartolome, Vasquez, \& Lucas, 1990). Differentiation in language arts begins with discussions based on big ideas of interest to young adolescents. Prime emphasis is placed on cultivating multiple perspectives in enriching students' understandings rather than closing them off as a result of preoccupation with consensus and uniformity (Applebee, 2002). Such discussions constitute differentiated oral responses and can lead eventually to rich differentiated written and creative responses to text.

\section{Dynamic Grouping}

Prevailing instructional and management practices often differ significantly from the elementary school. Students in middle school are involved in doing more worksheets, tests, and copying from the board and less involved in interaction with their peers (Irwin, 1998) at exactly a time when the nature of their language learning shifts to encompass more of a social context. 
Having students work in groups makes sense, as does having them use the appropriate level of reading materials to develop reading fluency (e.g. Roller, 1996). Yet teachers often use this as the sole criteria for grouping with little attention paid to other important criteria such as student's interest in particular topics, which is another important factor in reading achievement (e.g. Worthy et al., 2002). It has been demonstrated that group interactions around reading topics enhance students' interest in reading (Schiefele, 1991). Grouping criteria in a differentiated classroom would be flexible, sometimes according to their reading level or needs, while at other times, students would be grouped according to Kelly's and some of her peers' interest in such outdoor adventures as hiking the West Coast Trail on Vancouver Island. In such groups, teachers could draw on a range of reading materials from a variety of genres. Some members of her interest group would be reading more complex books on the topic, while Kelly's reading materials might consist of high-interest, low-vocabulary texts like those found in the Canada 2000 series (Kropp, 2000). If Sindu belonged to this interest group she might read brochures and magazines that contain lots of pictures and captions of the West Coast Trail, while Allie might draw on an expository article written for more sophisticated readers in McLean's magazine as part of her reading bundle. Helping students create a reading bundle made up of a variety of both narrative and expository texts across genres pre-empts them from closing off their research too early, thus avoiding only a superficial treatment of a topic.

One of the ways of keeping small groups functional and dynamic is to be clear about the purpose of the group and to change the group's composition often. For example, teachers may wish to bring together enactment groups-that is, teams of students who have an interest in a particular piece of literature. These teams prepare, rehearse, and present an enactment of a significant literary event or, when reading expository text, a particular historical or scientific 
event to the rest of the class or an audience beyond the class (Pappas, 2004). Another kind of group is the debate team which encourages students to sign up according to their own stance or position on a controversial issue of relevance to them. To participate in the debate, each team researches the issue and marshalls arguments for and against that particular topic.

Schneider (2000) offers suggestions for differentiating cooperative group work. For example, in a jigsaw reading of biographies, students are assigned different roles: a regular achieving reader could be responsible for classifying specific events in the reading; Kelly could be asked to make reader-friendly labels copied directly from a highlighted portion of the text; and Allie may be responsible for the more challenging task of creating metaphoric labels for the periods of each person's life. By differentiating tasks within cooperative groups learners are held accountable while ensuring that the work is suitably challenging for the entire group. At other times, students of similar abilities benefit from working together in their areas of greatest strengths (Rogers, 1993). It is the flexibility and purpose in grouping at various times and for various purposes that affords maximum differentiation. The skill lies in orchestrating the work so that learners bring their project to fruition in the form of a work product or culminating activity and preferably have an audience to enjoy and learn from their efforts. To accomplish this, experienced teachers schedule regular update meetings with their students. For example, in the early planning stage students show specific parts of the assignments which are completed such as a diagram, an outline, a poster, a model, a survey, a tableau, or a handout. This gives the teacher early indications of conceptual difficulties and misunderstandings that can be addressed early in the process. These meetings are held throughout the course of the project. It is one way to motivate group work and facilitate peer interactions around text. It is difficult to imagine meaningful differentiation without the management of dynamic and accountable groups. 


\section{Universal Design in Whole-Class Literacy Instruction}

Another way that teachers differentiate is through universal design in literacy instruction Universal design refers to a "designed-in" flexibility to accommodate the instructional needs of diverse learners in a single classroom (Orkwis \& McLane, 1998). The underlying premise of universal design is the largest number of people possible should benefit from products and environments without the need for additional modifications beyond those incorporated in the original design. Universal design implies that assistive supports are built-in rather than added on as an afterthought. The principles of universal design can be applied to a differentiated approach to whole group literacy instruction, in that individual differences are assumed and anticipated at the outset. For example, at the beginning stage in her language learning, Sindu requires context cues, repetition, visual support, removal of extraneous words in instructions, vocabulary development, and expansion of background knowledge in order to progress (Alvermann, 2000; Law \& Eckes, 2000). A teacher using universal design draws on all of these components when instructing the whole class. This is similar to the easy-grip handles on kitchen utensils that were originally developed for individuals with disabilities. It turns out that we all find kitchen utensils with such handles easier to use (Nolet \& McLaughlin, 2000). Such is also the case with Sindu's strategies - essential for her, yet they also make learning easier for all learners.

In a differentiated language arts classroom, such universal design, comprised of wellknown research-based practices, is commonplace. For example, it is now common knowledge that someone who knows a lot about rock climbing will comprehend a passage about it far more readily than someone who lacks such content-specific knowledge. Often, building up of such background knowledge prior to reading is accomplished through classroom strategies such as brainstorming or using Know/Wonder/Learn (KWL) (Ogle, 1989), by which students encounter 
similar and related vocabulary and chunks of words in meaningful contexts. Not only does this practice support comprehension for all learners, it also addresses the requirements of learners with special needs. For example, it introduces new vocabulary to Sindu, provides Kelly and Steven with the necessary preview of the vocabulary prior to their readings, while at the same time affording both Allie and Steven a chance to be divergent in their responses to such prompts as What are some of the challenges of Rock Climbing? or What supplies would you need? or How might you prepare for this sport? Inherent in universal design is redundancy in whole-class teaching, so that the teacher says it (through questioning, verbal description, read aloud); shows it (through pictures, graphics, transparency, white board, video); models it (through demonstrations, think aloud, constructions, manipulatives); and uses different media (such as video tape, internet, television, manipulatives, computer) (Nolet \& McLaughlin, 2000). Universal design differentiates by providing simultaneous ways of storing and retrieving information and using open-ended literacy strategies.

Access to multimedia

The saying "a picture is worth a thousand words" has unique relevance to gifted, students with LD, ESL, and struggling readers and writers who are dependent on visual images to retrieve information and build knowledge (Baum et al, 2001). In a differentiated classroom with an emphasis on multimedia, learners with these profiles could be involved in literacy practices using technology to assist them. Many students like Steven require teacher-directed learning environments, immediate feedback, and focused instruction which can be provided through carefully selected Web sites specifically tailored to educational content. Some sites provide activities that support both constructivist themes and a managed environment (Gardner \& Wissick, 2002). Teachers can get students started at sites like Education world : 
http://www.education-world.com/), which functions as a search engine and database for education-related information, or Blue Web'n (http://www.filamentality.com/wired/bluewebn/), where resources are organized based on curriculum themes. Sites like these provide a quick start for students and provide access to a wide range of Web-based activities that are often supportive of teachers' differentiated learning outcomes.

In addition, most teachers can learn to create web-based activities to support their own learning goals and write differentiated activities in less than thirty minutes by using a flexible online tool from a non-commercial site called TrackStar (http://trackstar.hprtec.org). For example, a web hunt is good way to engage students in a subject. During this kind of exercise, students answer questions along a continuum of complexity requiring them to search for specific information at specific Web pages (see http://www.filamentality.com/wired/fil/formats.html\#Hunt). Another example is a webquest, a problem-based learning activity that challenges students with a problem, question or scenario that requires higher-order thinking skills. In this exercise, students take on differentiated roles to analyze and synthesize information from the Web, and arrive at solutions and/or conclusions to the original challenge (see http://www.filamentality.com/wired/fil/formats.html\#WebQuest).

This is not to ignore the very real challenges that students with learning disabilities encounter in computer-based learning including (a) problems with navigation; (b) not remaining focused long enough to gain worthwhile information and (c) having problems forming relationships and seeing patterns (Wissick \& Gardner, 2000). Therefore critical analysis of Web sites is required in order to identify the additional instructions students like Steven, Kelly or Sindu might need to effectively process and perform corresponding activities.

$\underline{\text { Key Questions for the Novice }}$ 
For teachers accustomed to preparing one open-ended activity in language arts for the whole class, the initial prospect of differentiating may be daunting. The following five key questions about your current approach to planning and teaching the language arts, and about your beliefs and expectations about learner differences, may help in getting started and in establishing an environment that is conducive to differentiation. The subsequent questions may serve as a springboard for those of you already operating from a differentiated frame of reference.

(1) Do I prepare open-ended questions that include elementary inquiries about the text under study, such as "What is the story (or text) about?"? Applebee (2002) suggests that it is the expectation and acceptance of highly diverse answers to such a simple question, as well as the coaching of students in defending and elaborating upon their differentiated responses, that leads to student literary achievement. In preparing open-ended questions about the text, also be sure to include one or two that cause learners to connect with their personal experiences. Reflect on the range of students in your class and expect that all students will be able to envision or come up with a question, connection or concept related to previous knowledge or experiences (Langer, 1995).

(2) Do I facilitate flexible group interactions focused around a literacy activity? Our best understanding of how students learn suggests that they require social interaction in which they draw on previous understandings and knowledge to make sense of new concepts. A balance works best between teacher-led activities and those led by students, in which learners construct their developing understandings in establishing a differentiated environment. 
(3) Do I routinely facilitate choices in reading materials for learners across the ability

spectrum? It is critical to factor in not only reading levels, but reader interests, when considering the range of materials available to students in classrooms.

(4) Do I ask for and encourage creative work products and representations that acknowledge multi-modal literacies (Kress \& Jewitt, 2003)? In eliciting differentiated responses, it is important to acknowledge visual and creative representations that are often undervalued as students move up the grades.

(5) In direct instruction, do I routinely use visual displays, graphic organizers, repetition, and strategies to expand background knowledge? Our best understandings about the differentiated needs of second language learners, and students who struggle with reading and writing, suggests that these tools make learning easier ( Duffy-Hester, 1999; Law \& Ekes, 2000); yet it is not uncommon for teachers in the middle grades to rely uniquely on teacher talk, which can leave some students reaching for understanding.

If you have answered yes to the first five questions, than chances are that most of your students are engaged in meaningful literacy learning much of the time. To further develop a differentiated classroom, you may wish to consider the following questions:

(6) How often do I modify the content of the lesson or activity in response to what I know about the learner's background? This is frequently as simple as highlighting a section of the reading material, which focuses a reader on the key ideas, or providing a partially completed graphic organizer?

(7) How often do I provide mini-lessons for 1- 4 students? Such mini-lessons work best when there is a clear focus, such as building up background knowledge through the use of pictures and prompting questions. 
(8) How often in the school year do I take an interest inventory and base the new thematic or inquiry unit on some of the interests revealed?

(9) How well do I know my students as individuals? While much about students is revealed as they are engaged in open-ended and creative literacy activities as described in the first five questions, much more can also be learned from the array of information available in school records which details students' particular challenges and areas of relative strengths. It is especially important to know the learning profile of students who, for a variety of reasons, sometimes find literacy learning challenging.

(10) How often do students negotiate a variety of assignments including the assessment and evaluation criteria? Ultimately, differentiation involves sharing teacher power with the student so that they take responsibility for what is to be learned, how it is to be learned and how it is to be evaluated.

\section{$\underline{\text { Conclusion }}$}

Duffy and Hoffman (1999) note that good teachers are thoughtfully eclectic and are able to adapt to students and situations in context. Some good differentiation is the result of such opportunism and good judgement. This occurs when a teacher sees an unplanned opportunity present itself within a lesson and then builds on it as a result of a question or comment from a pupil, or from a student's work or a student's developing interest (Eyre, 1997). According to Tomlinson's 1995 model, differentiation asks good teachers to go beyond opportunism and to be proactive in anticipating some students' responses a) based on their profiles as revealed through school records; b) according to their interests as revealed through interest inventories and a growing knowledge of the students; and c) according to their readiness as revealed in their day- 
to-day interactions in class. As teachers facilitate rich discussions focused on big ideas, make use of universal design in whole class instruction, utilize dynamic grouping, provide choices in reading materials and work products, and provide better access to multimedia resources, the chances increase that students like Allie, Sindu, Steven, and Kelly will find multiple ways to participate in the language arts curriculum and get their individual needs met.

The current trend towards accountability and testing has promoted homogeneity and compliance in instructional approaches and perhaps lessened teachers' reliance on their own professional skills. Differentiation calls for more flexibility, divergence and confidence in one's professional ability to see difference in a learner and to respond appropriately. The labels of "gifted", "struggling reader", "learning disabled", and "culturally diverse" are often contested and understood in a variety of ways in the literature. What is not contested is the need for teachers and curricula that are responsive to the diverse needs and profiles of students.

Ultimately, teachers who choose to differentiate must be willing to share some of their power with their students and make curriculum decisions alongside them. They also need to cultivate a genuine interest in their students' ways of learning and their preferences for what and how they inquire. As Tomlinson argues, it is a "career-long evolution for a teacher to master the complex configuration of personal, professional, and leadership skills necessary to teach responsively in classrooms where the only guarantee is that students won't come as a matched set” (Tomlinson, 2004, p.55). 


\section{$\underline{\text { References }}$}

Adams, P. (1978). This is the house that Jack built. Swindon, U.K. : Child's Play International Ltd.

Alvermann, D.E. (2000). Grappling with the big issues in middle grades literacy education. Paper presented at National Educational Research Policy and Riorities Board's Conference. July 24-25. Washington, DC.

Applebee, A. N. (2002). Engaging students in the disciplines of English: What are effective schools doing? English Journal, July, 30-36.

Atwell, N. (1998). In the middle: New understandings about writing, reading, and literature $\left(2^{\text {nd }}\right.$ ed.). Toronto: Irwin Publishing.

Baum, S., Renzulli, J.S., \& Hebert, T. (1995). The prism metaphor : A new paradigm for reversing underachievement (CRS 95310). Storrs, CT: The National Research Center on the Gifted and Talented.

Baum, S., Cooper, C.R.,Neu, T. W. (2001). Dual differentiation: An approach for meeting the curricular needs of gifted students with learning disabilities. Psychology in the Schools, $38(5), 477-490$.

Bitz, M. (2004). The comic book project: Forging alternative pathways to literacy. Journal of Adolescent \& Adult Literacy, 47(7), 574-586.

Cummins, J. (2000). Language, power, and pedagogy: Bilingual children in the crossfire. Buffalo, NY: Multilingual Matters.

Duffy, G.G., \& Hoffman, J.V. (1999). In pursuit of an illusion: The flawed search for a perfect method. The Reading Teacher, 53, 10-16. 
Duffy-Hester, A.M. (1999). Teaching struggling readers in elementary classrooms: A review of classroom reading programs and principles for instruction. The Reading Teacher, 52, 480-495.

Dyson, A.H. (2003). The brothers and sisters learn to write: Popular literacies in childhood and school cultures. New York: Teachers College Press.

Eeds, M., \& Wells, D. (1989). Grand conversations: An exploration of meaning construction in literature study groups. Research in the Teaching of English, 23(1), 4-29.

Eyre, D. (1997). Able children in ordinary schools. London: David Fulton Publishers.

Fielding, L., \& Roller, C. (1992). Making difficult books accessible and easy books acceptable. The Reading Teacher, 46, 678-685.

Fink, R. (1995/6). Successful dyslexics: A constructivist study of passionate interest reading. Journal of Adolescent and Adult Literacy, 39, 268-280.

Gambrell, L. B., \& Almasi, J. F. (Eds.) (1996). Lively discussion! Fostering engaged reading. Newark, DE: International Reading Association.

Gardner, J. E. \& Wissick, C.A. (2002). Enhancing thematic units using the world wide web: Tools and strategies for students with mild disabilities. Journal of Special Education Technology, 17(1), 27-38.

Greenwood, S.C. (2002). Contracting revisited: Lessons learned in literacy differentiation. Journal of Adolescent \& Adult Literacy, v.46(4), 338-350.

Guthrie, J. T., Schafer, W., Wang, Y., \& Afflerbach, P. (1995). Relationships of instruction to amount of reading: An exploration of social, cognitive, and instructional connections. Reading Research Quarterly, 30(1), 8-25. 
Hidi, S. (1991). Interest and its contribution as a mental resource for learning. Review of Educational Research, 60, 549-571.

Hunter, P. C. (1999). Classroom libraries level the playing field. Instructor, 113(5), 36-40, 71.

Hutchinson, N.L. (2002). Inclusion of exceptional learners in Canadian schools: A practical handbook for teachers. Toronto: Prentice Hall

Irvin, J. (1998). Reading and the middle school student: Strategies to enhance literacy. Needham Heights, MA: Allyn \& Bacon.

Ivey, G. (2000). Redesigning reading instruction. Educational Leadership, 58(1), 42-45.

Kameenui, E. \& Carnine, D. (1998). Effective teaching strategies that accommodate diverse learners. Toronto: Prentice Hall.

Kress, G., \& Jewitt, C. (2003). Introduction. In C. Jewitt \& G. Dress (Eds.), Multimodal literacy (pp.1-18). New York: Peter Lang.

Kropp, P. (2000). Series Canada novels: St. Paul, MN: EMC Paradigm

Langer, J. A. (1995). Envisioning literature: Literary understanding and literature instruction. New York: Teachers College Press.

Langer, J. A., Bartolome, L., Vasquez, O., \& Lucas, T. (1990). Meaning construction in school literacy tasks : A study of bilingual students. American Educational Research Journal, $27,427-471$.

Law, B. \& Eckes, M. (2000). The more-than-just-surviving handbook: ESL for every classroom teacher. Winnipeg, MB: Peguis Publishers.

MacArthur, C., Schwartz, S., Graham, S., Molloy, D., \& Harris, K. R. (1996). Integration of strategy instruction into a whole language classroom: A case study. Learning Disabilities Research \& Practice, 11, 168-176. 
Mann, C.C. (2004). The giants of anime are coming. Wired, 9, 145-155, 171-173.

Morrell, E. (2002). Toward a critical pedagogy of popular culture: Literacy development among urban youth. Journal of Adolescent \& Adult Literacy, 46, 72-77.

Newkirk, T. (2002). Misreading masculinity: Boys, literacy and popular culture. Portsmouth, NH: Heinemann.

Nolet, V., \& McLaughlin, M. J. (2000). Accessing the general curriculum: Including students with disabilities in standards-based reform. Thousand Oaks, CA: Corwin Press.

Nystrand, M. (1997). Opening dialogue: Understanding the dynamics of language and learning in the English classroom. New York: Teachers College Press.

Ogle, D. M. (1989). The know, want to know, learn strategy. In K.D. Muth (Ed.), Children's comprehension of text: Research into practice (pp.205-223). Newark, DE: International Reading Association.

Orkwis, R. \& McLane, K. (1998). A curriculum every student can use: Design principles for student access. EEIC/OSEP Topical Brief. Reston, VA: Council for Exceptional Children.

Pappas, P. (2004). Managing small group learning. Retrieved on September 27, 2004 from http://www.edteck.com/blocks.

Pettig, K. L. (2000). On the road to differentiated practice. Educational Leadership, 58(1) 1418.

Renzulli, J.S. (1978). What makes giftedness? Re-examining a definition. Phi Delta Kappan, 60,180-184, 261.

Renzulli, J. S.\& Reis, S. M. (1997). The Schoolwide enrichment model : A how-to guide for educational excellence. Mansfield Center, CT: Creative Learning Press 
Rogers, K. (1993). Grouping the gifted and talented. Roeper Review, 16(1), 8-12.

Roller, C.M. (1996). Variability not disability: Struggling readers in a workshop classroom. Newark, DE: International Reading Association.

Schiefele, U. (1991). Interest, learning, and motivation. Educational Psychologist, 26, 2999323.

Schneider, E. (2000). Shifting into high gear. Educational leadership, 58(1), 57-60.

Singer, H., \& Donlan, D. (1989). Reading and learning from text. Hillsdale, NJ:Erlbaum.

Tannenbaum, A.J. (1983). Gifted children: Psychological and educational perspectives. New York: Macmillan.

Taylor, C. (1992). The house that crack built. San Francisco: Chronicle Books.

Tieso, C. (2003). Ability grouping is not just tracking anymore. Roeper Review, 26(1), 29-36.

Toku, M. (2001). What is manga?: The influence of pop culture in adolescent art. Art Education, 54(2), 11-17.

Tomlinson, C.A. (1995). How to differentiate instruction in mixed-ability classrooms. Alexandria, VA: Association for Supervision and Curriculum Development.

Tomlinson, C.A. (1999). The Differentiated Classroom. Association for Supervision and Curriculum Development. Alexandria, VA.

Tomlinson, C.A. (2004). Sharing responsibility for differentiating instruction. Roeper Review, 26(4), 188-189.

Towle, W. (2000). The Art of the Reading Workshop. Educational Leadership, 58(1), 38-41.

Van Tassel-Baska, J. (1992). Planning effective curriculum for gifted learners. Denver, Co: Love Publications.

Vygotsky, L.S. (1962). Thought and Language. Cambridge: MIT Press. 
Wells, G. (2001). Action, talk, and text: Learning \& teaching through inquiry. Learning \& teaching through inquiry. New York: Teachers College Press.

Wilson, B. (1997). Types of child art and alternative developmental accounts: Interpreting the interpreters. Human Development, 40(3), 155-168.

Winebrenner, S. (2001). Teaching gifted kids in the regular classroom (rev. ed.). MN.: Free Spirit.

Wissick, C.A. \& Gardner, J.E. (2000). Multimedia or not to multimedia? That is the question for students with learning disabilities. Teaching Exceptional Children, 32(4), 34-43.

Worthy, J. (1996). A matter of interest: Literature that hooks reluctant readers and keeps them reading. The Reading Teacher, 50, 204-212.

Worthy, J. Patterson, E., Salas, R., Prater, S., Turner, M. (2002). “More than just reading”: The human factor in reaching resistant readers. Reading Research and Instruction, 41(2), 177-201. 